\title{
Fuzzy Logic Control of Soft-Switching DC-DC Converter
}

\author{
Martin Leso ${ }^{1}$, Jaroslava Zilkova ${ }^{1}$, Marek Pastor ${ }^{1}$, Jaroslav Dudrik ${ }^{1}$ \\ ${ }^{I}$ Department of Electrical Engineering and Mechatronics, Faculty of Electrical Engineering and \\ Informatics, Technical University of Kosice, \\ Letna 9, 04200 Kosice, Slovakia \\ martin.leso@tuke.sk
}

\begin{abstract}
The paper presents a novel control technique for a phase-shifted PWM (PS-PWM) soft-switching dc-dc converter. The converter is a full bridge dc-dc converter with controlled output rectifier and an active snubber on the secondary side. To solve the problems with nonlinear nature of the dc-dc converter a fuzzy logic control is used. The fuzzy logic controller design and simulation is presented. The performance of the designed fuzzy logic controller is compared to classical PI controller.
\end{abstract}

Index Terms-DC-DC converter; fuzzy logic controller; soft switching.

\section{INTRODUCTION}

The dc-dc converters are part of many applications including grid-tied and standalone photovoltaic systems, fuel cells generators, electrical vehicles, battery chargers. In all of these applications the high efficiency and small dimensions and weight are required. To decrease the size of the converters the switching frequency is increased to enable small reactive components [1]-[5]. However, the increase of the switching frequency has a consequence in the proportional increase of switching losses in the semiconductor switches [1], [6].

The soft-switching dc-dc converters minimise the switching losses, independently to switching frequency, by incorporating zero-current (ZCS) and/or zero-voltage switching (ZVS). There are various techniques how to reach ZVS or ZCS depending on the converter topology. The fullbridge dc-dc converter can use active rectifier which ensures the soft-switching (ZCS) of the primary side transistors [2], [4]. Then some kind of a snubber on the secondary side diminishes the switching losses of the secondary side transistors [2]-[4].

This kind of dc-dc converters uses two control algorithms. The primary controller ensures the soft-switching and is usually based on the phase-shifted (PS) PWM with proper switching timing of the secondary side transistors [1], [4]. Then a secondary voltage controller has to be used to control

Manuscript received 21 December, 2015; accepted 23 May, 2016.

This work was supported by the Slovak Research and Development Agency under the contract No. APVV-0185-10. The authors wish to thank the project VEGA $1 / 0464 / 15$ for its support. The work was supported by FEI-2015-3. the output voltage of the converter. Many papers usually deal with the topology and the basic soft-switching controller [1]-[4], [6]. But they usually lack the design of the secondary voltage controller which is necessary to have a fully functional dc-dc converter.

There are several techniques which can be adapted in the voltage controller of the $\mathrm{dc}-\mathrm{dc}$ converter. One can use classical linear control technique. The downside of this approach is that the dc-dc converter has higher order, and usually not a linear nature, and the PID controller cannot ensure the optimal control under any condition, e.g. load change, output voltage change, etc. With the development of fast microprocessors, the implementation of modern control techniques for various power converters is possible [7]. They include fuzzy logic, sliding mode, predictive control and others [8], [9].

The fuzzy logic control is suitable for systems, where some control system parameters are unknown [10]. This control technique is used nowadays in many applications [11] including electrical drives and power converters [12], [13]-[16] automation technique [17], mobile robotics [18], etc. The downside of the fuzzy logic controller is high demand on computational power, which is not a problem with modern DSPs.

The paper presents design and simulation of a fuzzy logic controller for a soft-switching full-bridge PWM dc-dc converter with controlled output rectifier and secondary turn-off snubber presented in [4]. This converter has a PI controller and the dynamic performance of the designed fuzzy logic controller is compared to the original PI controller as well.

\section{SOFT-SWitching CONVERTER TOPOLOGY}

The soft-switching full-bridge PWM dc-dc converter with controlled output rectifier and secondary turn-off snubber, shown in Fig. 1, is described in detail in [4]. In order to design a fuzzy logic output voltage controller, it is not necessary to know the detailed operation of the softswitching technique used in this converter. The softswitching is ensured by a primary controller and its control algorithm is described in [4]. Parameters of the dc-dc converter are shown in Table I and laboratory model of converter in Fig. 2. 


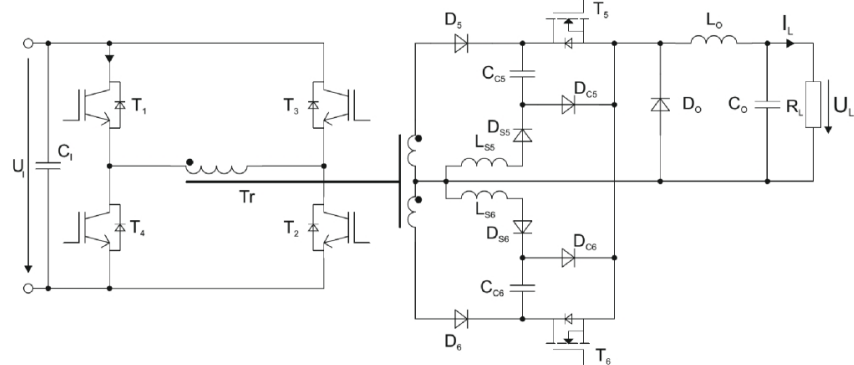

Fig. 1. Scheme of the full-bridge PWM dc-dc converter with controlled output rectifier and secondary energy recovery turn-off snubber.

TABLE I. DC-DC CONVERTER PARAMETERS.
\begin{tabular}{|c|c|c|}
\hline Parameter & Value & Unit \\
\hline Input voltage $\mathrm{U}_{\mathrm{I}}$ & 325 & $\mathrm{~V}$ \\
\hline Switching frequency $\mathrm{f}_{\mathrm{s}}$ & 100 & $\mathrm{kHz}$ \\
\hline Rated output power $\mathrm{P}$ & 4.5 & $\mathrm{~kW}$ \\
\hline Load resistance $\mathrm{R}_{\mathrm{L}}$ & $10 / 0.01$ & $\Omega$ \\
\hline Filter inductance $\mathrm{L}_{\mathrm{o}}$ & 4 & $\mu \mathrm{H}$ \\
\hline Filter capacitance $\mathrm{C}_{\mathrm{o}}$ & 100 & $\mu \mathrm{F}$ \\
\hline Transformer voltage ratio $\mathrm{p}$ & 5 & - \\
\hline
\end{tabular}

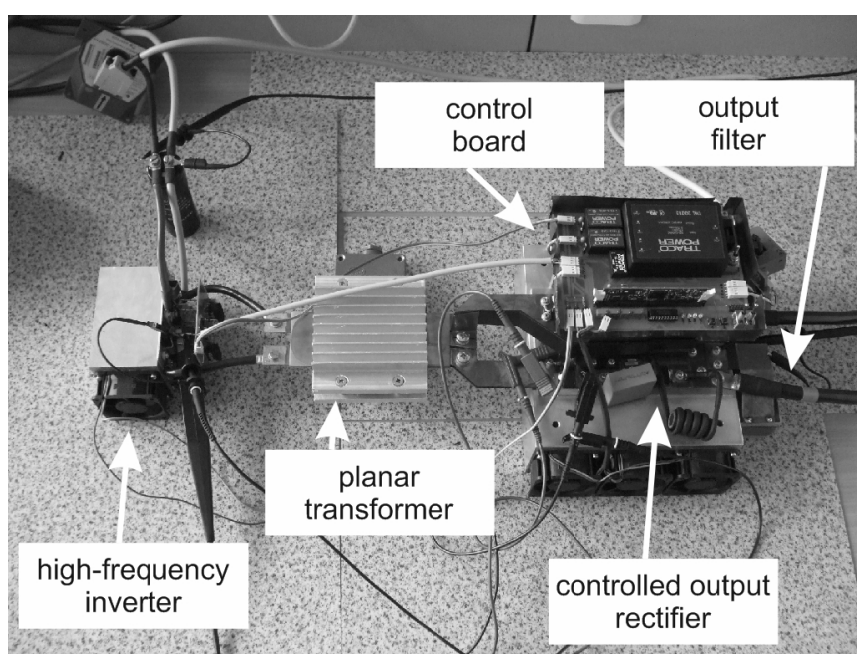

Fig. 2. Laboratory model of dc-dc converter.

\section{ORIGINAL CONTROL SCHEME}

The original overall control scheme of dc-dc converter has been designed in MATLAB/Simulink. The control scheme consists of a PI current controller (which provides overload protection of circuit, adjustable by parameter $i_{L}^{*}$ ), voltage controller, switching logic between controllers and dc-dc converter with load resistance $R_{L}$. shown in Fig. 3.

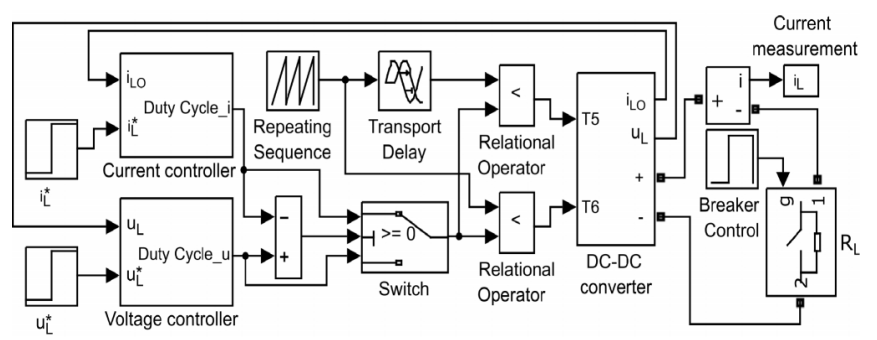

Fig. 3. Overall Simulation scheme.

\section{A. Simulation Scheme of DC-DC Converter}

The simulation model of the dc-dc converter is shown in Fig. 3 and has been created in Simscape Power System library of MATLAB/Simulink according to scheme of dc-dc converter shown in Fig. 4.

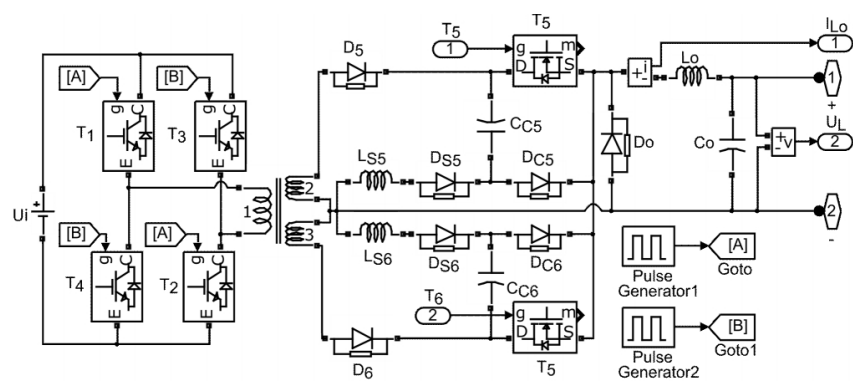

Fig. 4. Model of the dc-dc converter.

The pulse generator 1 and the pulse generator 2 generate switching impulses for transistors of inverter $T_{I}-T_{4}$ which are creating high frequency voltage transmitted to a rectifier by step-down planar transformer. The rectifier consists of MOSFET transistors $T_{5}, T_{6}$ with diodes $D_{5}, D_{6}$, which are connected to output filter consisting of $L_{0}$ and $C_{0}$ to smooth the output voltage.

The secondary energy recovery turn-off snubber, consisting of diodes $D_{S 5}, D_{C 5}, D_{S 6}, D_{C 6}$ capacitors $C_{C 5}, C_{C 6}$ and inductances $L_{S 5}, L_{S 6}$, minimizes the turn-off switching losses of the rectifier transistors.

\section{B. PI Controllers}

The gating pulses for rectifier are generated by pulse width modulation. The PWM triangular waveform with frequency of $100 \mathrm{kHz}$ is compared to control signal generated by voltage PI controller or current PI controller. The controller with a smaller control move is chosen as active one. The gating pulses of rectifier are synchronized with gating pulses of inverter.

The structure of the original voltage PI controller is shown in Fig. 5. The controller computes the control error $e$ based on signal $u_{L}^{*}$ and $u_{L}$. The control error is processed by the block "data processing" which includes first-order filter with time constant equal to 200 ns. The PI controller sampling time was $5 \mu \mathrm{s}$.

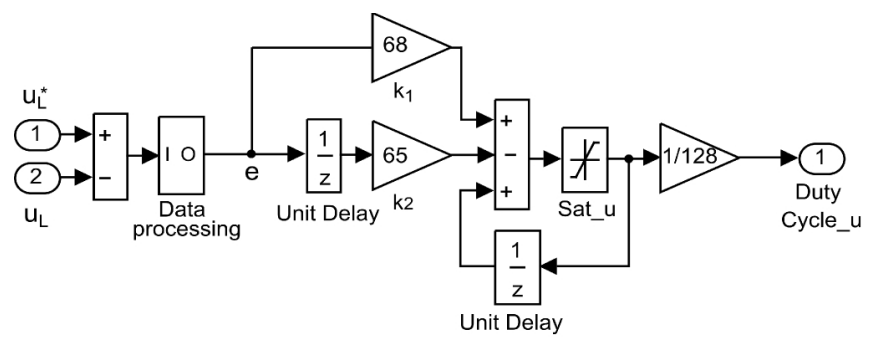

Fig. 5. Voltage PI controller.

The controller integral and proportional terms are not clearly defined and are included in constant $k_{1}$ and $k_{2}$ according [20]. The limiter Sat_ $u$ is used, to limit maximum duty cycle to $85 \%$ of maximum value.

The scheme of current controller is similar to voltage controller and only difference is in PI controller gains.

\section{FuZZY Logic CONTROLLER DESIGN}

\section{A. Structure of Voltage Fuzzy Logic Controller}

To improve quality of output voltage control the PI fuzzy logic controller (FLC) was designed. The structure of voltage fuzzy logic controller is similar to PI voltage 
controller and it is shown in Fig. 6. The controller computes regulation error $e$ based on the signal $u_{L}^{*}$ and $u_{L}(1)$, which is processed by the block "data processing" which includes filtering of $e$ with first-order filter with time constant equal to $200 \mathrm{~ns}$, which is quantized to 12 -bit discrete number. From this value there is computed $\Delta e(2)$. Both $\Delta e$ and $e$ are normalized and limited in interval $\{-1,1\}$ and used as input for FLC. The output of voltage controller is duty cycle, which is computed as integer of normalized output of FLC $\Delta u$.

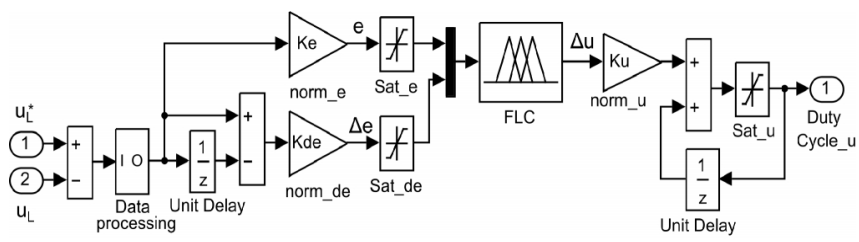

Fig. 6. Voltage FLC.

\section{B. Interal Structure of Voltage PI Fuzzy Controller}

In this paper, Mamdani PI type of FLC has been used. The block diagram of the FLC (Fig. 2(b)) consists of five blocks, which are shown in Fig. 7.

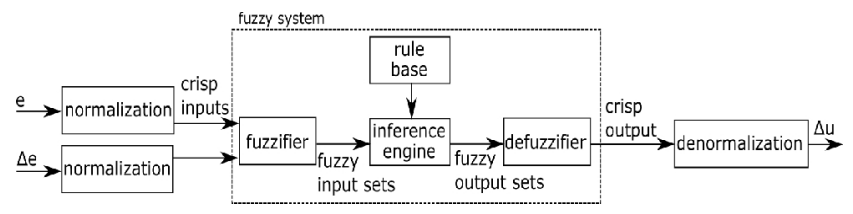

Fig. 7. Block scheme of the fuzzy controller.

The inputs of the FLC are two variables $e, \Delta e$ (Fig. 3). As given in (1), the error is the difference between the actual set point of the output voltage $u_{L}{ }^{*}$ and the actual value of the output voltage $u_{L}$

$$
e(k)=u_{L}^{*}(k)-u_{L}(k) .
$$

The change in error $\Delta e(k)$ is given by (2)

$$
\Delta e(k)=e(k)-e(k-1)
$$

In the block of normalization (Fig. 7) the input values $(e, \Delta e)$ are scaled in the range $\{-1,1\}$ by the two normalization parameters $(K e, K d e)$.

In the block of fuzzifier, the crisp normalized values $(e, \Delta e)$ are converted into fuzzy values by five triangular and trapezoidal fuzzy membership functions, which are defined for the input values. There are many types of different membership functions, obviously a triangular and trapezoidal membership functions are often used for digital implementation, due to their simple forms and high computational efficiency [10].

The fuzzy inputs values $(e, \Delta e)$ membership functions with five linguistic variables noted as: Negative Large (NL), Negative Small (NS), Zero (Z), Positive Small (PS) and Positive Large (PL) are show in Fig. 8(a), Fig. 8(b). Trapezoidal fuzzy membership function $\mathrm{Z}$ in Fig. 8(b) was chosen due to suppression of PWM oscillations.

The block of rule base (Fig. 7) of FLC is based on the experience. In our case, 25 rules have been used which are shown in Table. II.
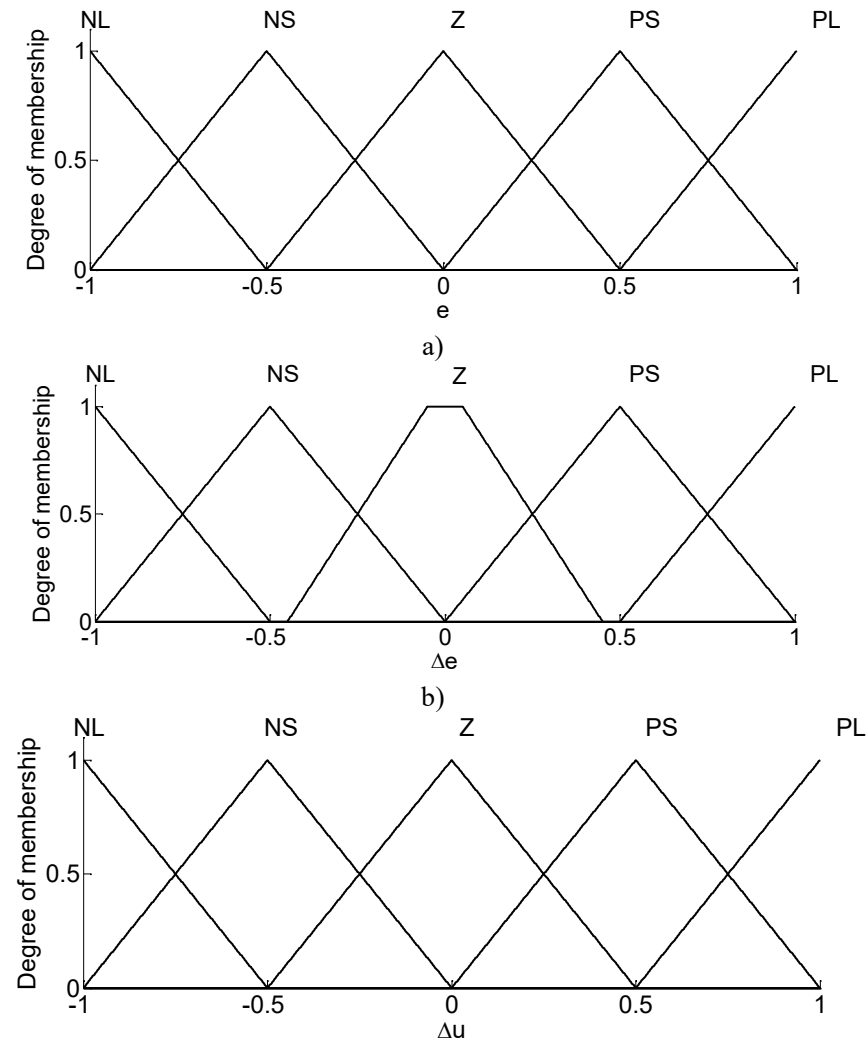

c)

Fig. 8. Membership functions: (a) $e$, (b) $\Delta e$, (c) $\Delta u$.

TABLE II. FLC RULE TABLE.

\begin{tabular}{|c|c|c|c|c|c|}
\hline$\Delta$ ele & NL & NS & $Z$ & PS & PL \\
\hline NL & NL & NL & NS & NS & Z \\
\hline NS & NL & NS & NS & Z & PS \\
\hline Z & NS & NS & Z & PS & PS \\
\hline PS & NS & Z & PS & PS & PL \\
\hline PL & Z & PS & PS & PL & PL \\
\hline
\end{tabular}

For the fuzzy voltage controller has been used fuzzy rules in the following form, example for two rules:

if $e$ is $\mathrm{NL}$ and $\Delta e$ is NL then $\Delta u$ is NL,

if $e$ is NL and $\Delta e$ is NS then $\Delta u$ is NL.

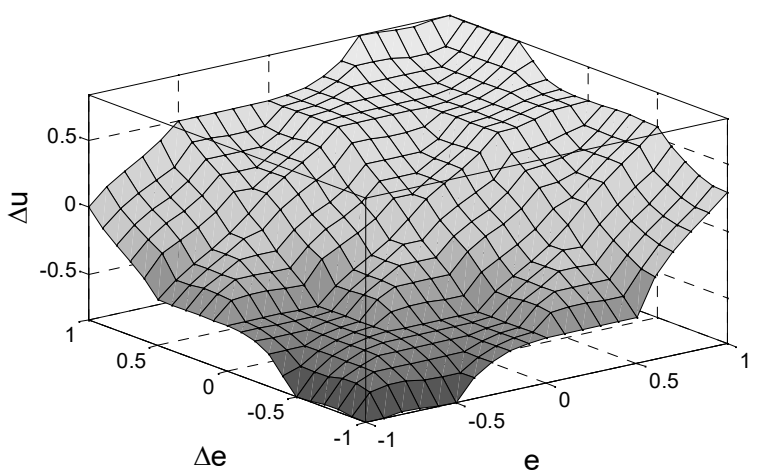

Fig. 9. The control surface of FLC.

In the block of interference (Fig. 7) the max-min compositional rule of inference has been used. The membership functions used for obtaining fuzzy output value $\Delta u$ are shown in Fig. 8(c)). The notice of the membership functions of the output value are identical to notice of inputs 
membership functions. The output fuzzy values obtained in inference block has been converted to crisp value $\Delta u$ by process of defuzzification. The centre of gravity method has been used in the defuzzification block in Fig. 3.

The denormalization block converts the crisp output value $\Delta u$ into value of duty cycle by denormalization constant $(K d u)$.

In Fig. 9 is shown FLC surface, which graphically describes the dynamics of the fuzzy logic controller.

\section{Simulation Results}

The performance of the designed fuzzy logic controller was verified by simulation in MATLAB/Simulink and Fuzzy Logic Toolbox.

The simulation was performed for two different output voltage levels. The dc-dc converter is designed as a stepdown converter. The input voltage $U_{I}$ (Fig. 1) was set to $325 \mathrm{~V}$, the switching frequency was $100 \mathrm{kHz}$. To test the dynamics of the fuzzy logic voltage controller a step in the load resistance was created. The load resistance $R_{L}$ was stepped from $10 \Omega$ to $0.01 \Omega$. The designed PI fuzzy logic controller is compared to the original PI controller implemented in the dc-dc converter.

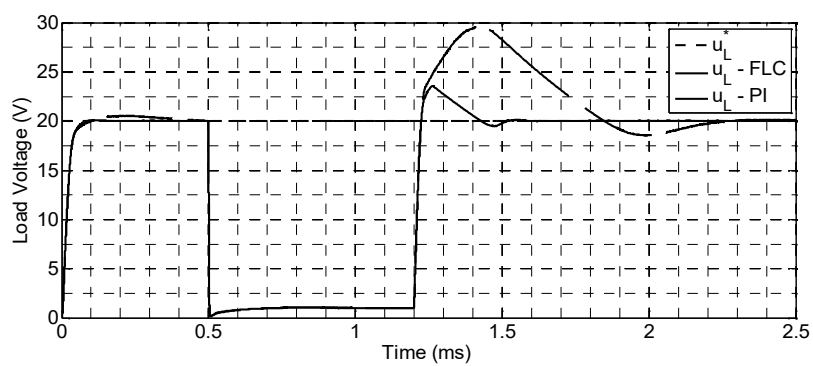

Fig. 10. Comparison of load voltage control of PI and FLC for output voltage $20 \mathrm{~V}$.

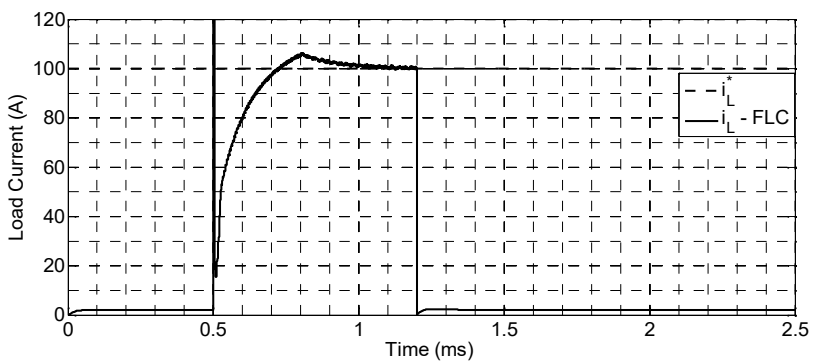

Fig. 11. Comparison of load current control of PI and FLC for output voltage $20 \mathrm{~V}$.

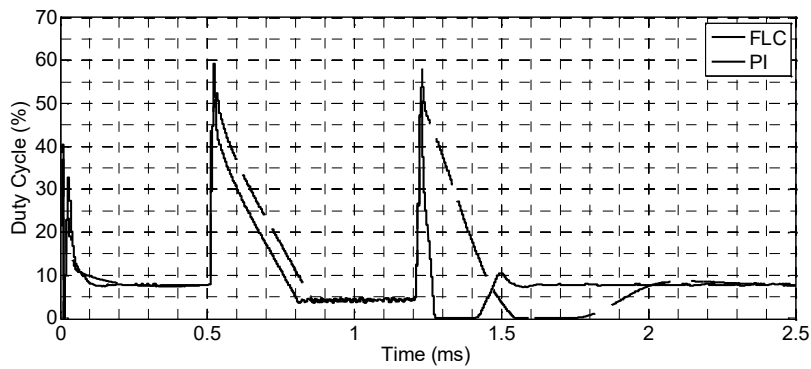

Fig. 12. Comparison of $T_{5}$ and $T_{6}$ duty cycle for PI and FLC for output voltage $20 \mathrm{~V}$.

At first the output voltage set point was set to $20 \mathrm{~V}$. The simulation results are shown in Fig. 10. At first the start-up of the converter is shown. Compared to the PI controller the fuzzy logic controller has no overshot. Then at $t=0.5 \mathrm{~ms}$ the load resistance $\mathrm{R}_{\mathrm{L}}$ was changed to $0.01 \Omega$ and at $t=1.2 \mathrm{~ms}$ the load resistance was stepped back to $10 \Omega$. The difference between PI and fuzzy logic controller is significant. The fuzzy logic controller has significantly shorter settling time and overshot. The output current is shown in Fig. 11. The output current was set to $100 \mathrm{~A}$. The corresponding duty cycle of transistors $T_{5}$ and $T_{6}$ is shown in Fig. 12.

The similar simulation was done for the output voltage set-point of $45 \mathrm{~V}$. The change of the output voltage set-point forces the converter to operate with different duty-cycle and its transfer function will be different. The corresponding simulation results can be found in Fig. 13 to Fig. 15. The designed PI fuzzy logic controller is superior to original linear PI controller when comparing settling time.

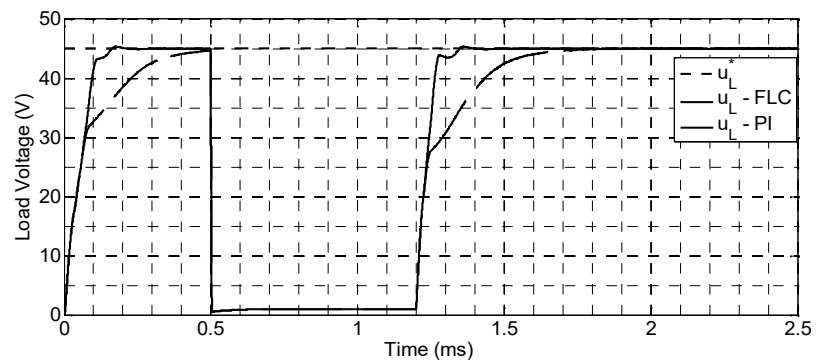

Fig. 13. Comparison of load voltage control of PI and FLC for output voltage $45 \mathrm{~V}$.

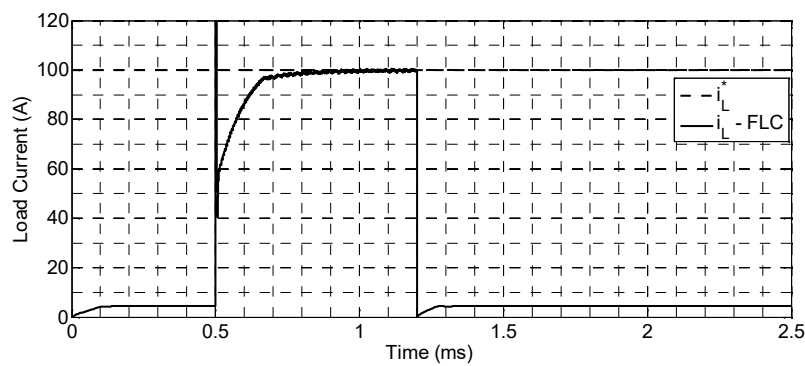

Fig. 14. Comparison of load current control of PI and FLC for output voltage $45 \mathrm{~V}$.

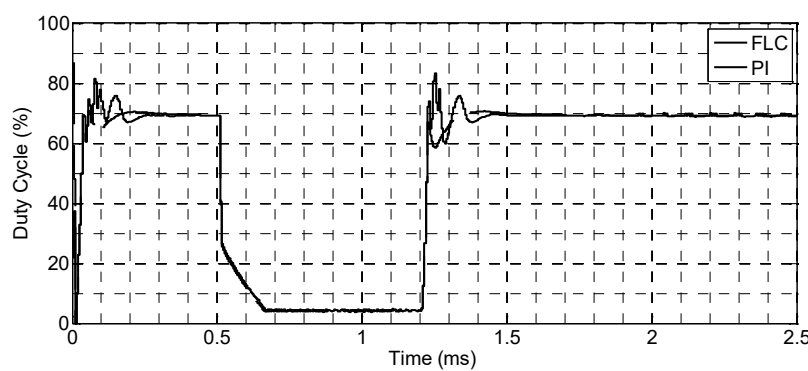

Fig. 15. Comparison of $\mathrm{T}_{5}$ and $\mathrm{T}_{6}$ duty cycle for PI and FLC for output voltage $45 \mathrm{~V}$.

The duty cycle of the secondary transistors $T_{5}$ and $T_{6}$ has more abrupt changes in the case of the fuzzy logic controller as it has higher dynamics than the original PI controller. The rate of change of the duty cycle is defined by fuzzy logic controller rules. The abrupt change of the control variable (duty cycle of the $\mathrm{T}_{5}$ and $\mathrm{T}_{6}$ transistors) is not a problem in the case of a semiconductor dc-dc converter.

\section{CONCLUSIONS}

The paper presents design and simulation verification of the output voltage fuzzy logic controller for the full-bridge 
soft-switching dc-dc converter. The detailed design of the PI fuzzy logic controller is described. Then the suggested fuzzy logic control technique is compared to classical linear PI controller which was already implemented in the converter.

The simulation results show improved performance of the converter with fuzzy logic controller. The nonlinear nature of FLC is able to achieve better result compared to linear PI control. During start-up of converter with lower output voltage, FLC shows similar settling time as PI controller without any overshoot. With increased voltage set point FLC shows significantly faster settling time with overshoot up to $1 \%$. After removal of short circuit, the FLC achieved significantly faster response with no overshoot. The key to improvement of the dc-dc converter dynamics with FLC is utilising the information of control error and its derivate to change of duty cycle, which permits much higher rate of change of duty of cycle of the rectifier transistors and also smaller change of duty cycle near set up value.

One of the disadvantage of using the FLC is more challenging design and more complicated tuning due many parameters such as normalization constant, rules definition and shape of membership functions, which tuning also require deeper analysis and understanding of the behavior of the converter. In opposite, one of the major advantages of this control is that there is no need to know mathematical model of converter, so the control method is more robust to parameters change. The most significantly downside of the FLC is its computational and memory demand, which can lead to requirement to use more expensive microcontroller.

The presented soft-switching converter can be used in many applications. It was primarily designed for low output voltages and high current. This feature is suitable for welding applications, battery chargers, and general dc-dc converters. The output voltage overshoot reduced by the designed PI fuzzy logic voltage controller can protect voltage sensitive devices supplied by the dc-dc converter. The robustness of a fuzzy logic controller makes it suitable for variable output voltages.

\section{REFERENCES}

[1] H.-S. Choi, J.-W. Kim, B. H. Cho, "Novel zero-voltage and zerocurrent-switching (ZVZCS) full-bridge PWM converter using coupled output inductor", IEEE Trans. Power Electron., vol. 17, no. 5, pp. 641-648, 2002. [Online]. Available: http://dx.doi.org/ 10.1109/TPEL.2002.802179

[2] J. Dudrik, V. Ruscin, "ZVZCS PWM DC-DC converter with controlled output rectifier", Acta Electrotechnika et Informatica, vol. 10, no. 1, pp. 12-17, 2010.

[3] M. Bodor, J. Dudrik, J. Perdulak, "ZVZCS PWM converter using secondary active clamp", Acta Electrotechnica et Informatica, vol. 11, no. 3, pp. 26-30, 2011, [Online]. Available: http://dx.doi.org/10.2478/v10198-011-0026-7

[4] J. Dudrik, M. Bodor, M. Pastor, "Soft-switching full-bridge PWM DC-DC converter with controlled output rectifier and secondary energy recovery turn-off snubber", IEEE Trans. Power Electronics, vol. 29, no. 8, pp. 4116-4125, 2014, [Online]. Available: http://dx.doi.org/10.1109/TPEL.2013.2293537

[5] P. Spanik, P. Drgona, M. Frivaldsky, A. Prikopova, "Design and application of full digital control system for LLC multiresonant converter", Elektronika ir Elektrotechnika, vol. 10, no. 106, pp. 75$78,2010$.

[6] R. Zatkovic, "Soft switching high frequency DC-DC converters with secondary side active rectifier and snubber", in Proc. SCYR 2015, Kosice, 2015, pp. 119-122.

[7] B. Bednar, V. Blahnik, P. Drabek, M. Pittermann, "Novel control strategy of single matrix traction converter - variable switching frequency", Elektronika ir Elektrotechnika, vol. 21, no. 5, pp. 13-18, 2015. [Online]. Available: http://dx.doi.org/10.5755 j01.eee.21.5.13318

[8] P. Cortes, M. P. Kazmierkowski, R. M. Kennel, D. E. Quevedo, J. Rodriguez, "Predictive control in power electronics and drives", IEEE Trans. Industrial Electronics, vol. 55, no. 12, pp. 4312-4324, 2008. [Online]. Available: http://dx.doi.org/10.1109/ TIE.2008.2007480

[9] M. Pastor, J. Dudrik, M. Vacek, "Predictive power control of gridtied multilevel inverter", Acta Electrotechnica et Informatica, vol. 13, no. 3, pp. 3-7, 2013.

[10] J. Vascak, Fuzzy Systems. TU Kosice, 2015, pp.115.

[11] I. Sohail, Fuzzy Controllers - Recent Advances in Theory and Applications. Rijeka, Croatia: InTech, 2012. [Online]. Available: http://dx.doi.org/10.5772/2622

[12] P. Brandstetter, A.C. Drives - Modern Control Methods. VSB-TU Ostrava, 1999, pp. 12-193.

[13] P. Vas, Artifical-Inteligence-Based Electrical Machines and Drives. Oxford Press, New York, 1999.

[14] M. P. Kazmierkowski, R. Krishnan, Frede Blaabjerg, Control in Power Electronics-Selected Problems. Elsevier Science, San Diego, 2002.

[15] M. Louzazni, E. Aroudam, "Control and stabilization of three-phase grid connected photovoltaics using PID-Fuzzy logic", IEEE Int. Conf. Intelligent Energy and Power Systems (IEPS), 2014, pp. 279-284. [Online]. Available: http://dx.doi.org/10.1109/ IEPS.2014.6874195

[16] L. Guo, J. Y. Hung, R. M. Nelms, "Evaluation of DSP-Based PID and fuzzy controllers for DC-DC converters", IEEE Trans. Industrial Electronics, vol. 56, no. 6, pp. 2237-2248, 2009. [Online]. Available: http://dx.doi.org/10.1109/tie.2009.2016955

[17] P. Fedor, D. Perdukova, "A simple fuzzy controller structure", Acta Electrotechnica et Informatica, vol. 5, no. 4, pp. 53-56, 2005.

[18] J. Bacik, D. Perdukova, P. Fedor, "Design of fuzzy controller for hexacopter position control", Advances in Intelligent Systems and Computing, vol. 347, pp. 193-202, 2015. [Online]. Available: http://dx.doi.org/10.1007/978-3-319-18476-020

[19] V. Marik, O. Stepankova, J. Lazansky, et al., Artificial Inteligence. Academia, Prague, 2003

[20] A. S. Anuchin, "Structures of a digital PI controller for an electric drive", Russ. Electr. Engin, no. 7, pp. 2-6, 2014. 